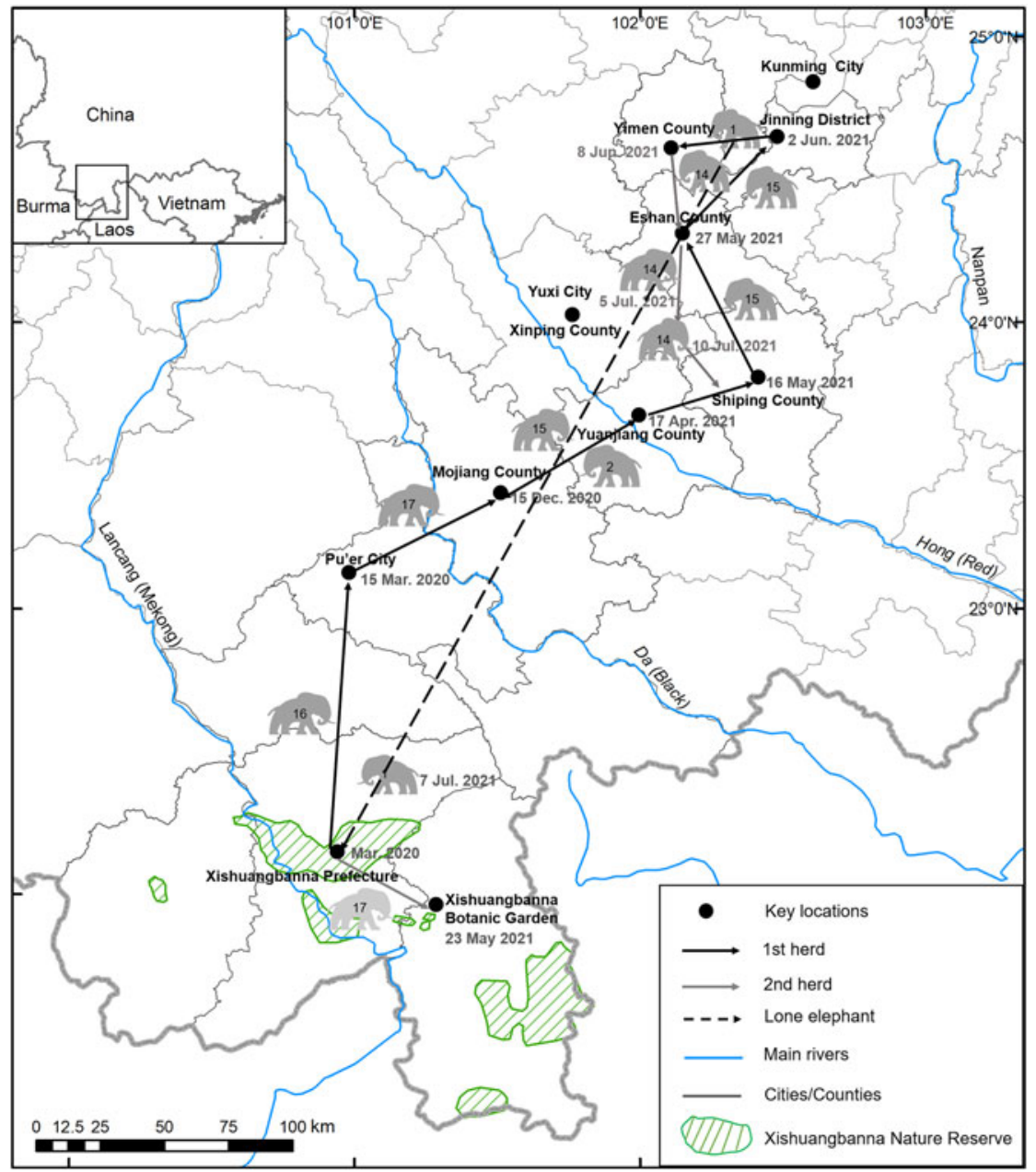

The movement paths of wild Asian elephants Elephas maximus from the Xishuangbanna National Nature Reserve to Kunming City and to Xishuanbanna Botanic Garden, Yunnan, China.

\section{IUCN launches Green Status of Species: a new standard for species recovery}

In summer 2021, IUCN launched the Green Status of Species, an optimistic new part of the Red List of Threatened Species that provides a tool for assessing species recovery and the impact of conservation. The Green Status of Species assesses three facets of recovery. A species is Fully Recovered (or Non-Depleted) if, in all parts of its indigenous range (areas that were occupied prior to major human impacts), it is (1) present, (2) viable (i.e. not threatened with extinction), and (3) ecologically functional.

These factors contribute towards a Green Score in the range 0-100\%, which shows how far a species is from its Fully Recovered state. This score is converted into recovery categories that mirror those of the Red List (e.g. Critically Depleted, Slightly Depleted). This definition of recovery is ambitious by design. It is not expected, nor is it a goal, that all species will eventually fulfil this definition of full recovery; for many species, large areas within their range have been irrevocably modified. Rather, this definition serves to standardize the assessment approach between species, and to identify areas of recovery opportunity in the context of what has been lost.
The Green Status of Species reports not only a species' current Green Score and corresponding recovery category, but also how conservation actions have affected the current status, what we might expect if conservation actions are halted, and how a species' status could improve in the future with conservation action. The past or potential impact of conservation action is captured in a set of conservation impact metrics, based on Green Scores calculated for different times and scenarios (Grace et al., 2021, Conservation Biology, dx.doi.org/10.1111/cobi.13756).

The Green Status of Species was developed following an IUCN Resolution that called for development of Green Lists of Species, Ecosystems and Protected Areas. The Green Status of Species therefore began development under the name Green List of Species (Akcakaya et al., 2018, Conservation Biology, 32, 1128-1138). Consultations during development indicated the name should be changed to Green Status of Species, to avoid the misconception that a species assessed on a Green List is no longer in need of conservation and any potential confusion with the IUCN Green List of Protected and Conserved Areas (Grace et al., 2021, Conservation and Society, in press).

For further information on the Green Status of Species, and to download a copy of the new Standard, see the IUCN Red 
List website (iucnredlist.org/about/green-status-species). Green Status of Species assessments will be published on the IUCN Red List website as they become available.

MOLLY K. GRACE (@ orcid.org/0000-0002-1978-615X) Department of Zoology, and Wadham College, University of Oxford, Oxford, UK. E-mail molly.grace@zoo.ox.ac.uk

ELIZABETH L. BENNETT Wildlife Conservation Society, New York, USA

H. REŞIT AKÇAKAYA (৫ orcid.org/0000-0002-8679-5929) Department of Ecology and Evolution, Stony Brook University, New York, USA

CRAig Hilton-TaYlor (@ orcid.org/0000-0003-1163-1425) IUCN, Cambridge, UK

Michael HoffMANN (๑ orcid.org/0000-0003-4785-2254) Zoological Society of London, London, UK

RichaRd JeNkINs IUCN Global Species Programme, Cambridge, UK

E.J. MilneR-Gulland (๑ orcid.org/0000-0003-0324-2710) Merton College, University of Oxford, Oxford, UK

ANA NIETO IUCN Global Species \& Key Biodiversity Areas Programme, Gland, Switzerland

RICHARD P. YOUNG (๑ orcid.org/0000-0002-6515-6343) Durrell Wildlife Conservation Trust, Jersey, British Channel Islands

BARNEY LONG (๑ orcid.org/0000-0002-9747-6042) Re:wild, Austin, USA

This is an Open Access article, distributed under the terms of the Creative Commons Attribution licence CC BY 4.0.

\section{A new breeding site of Hornby's storm petrel}

Hornby's storm petrel Oceanodroma hornbyi is a species endemic to the Humboldt Current Region of South America and one of the least known seabirds. Its population size is poorly documented, having been estimated in 2007 at 637,000-1,011,900 individuals, through open ocean counts (Spear \& Ainley, 2007, Ornithological Monographs, 62, 177). The species is categorized as Near Threatened on the IUCN Red List as the known area of its breeding colonies is small, and the species may be declining as a result of light pollution. In Chile, the species is categorized as Vulnerable, and its range includes northern coasts from the Tarapacá to the Atacama Regions.

The only known colony of Hornby's storm petrel is in Pampa de Indio Muerto in the Atacama Desert, Chile,

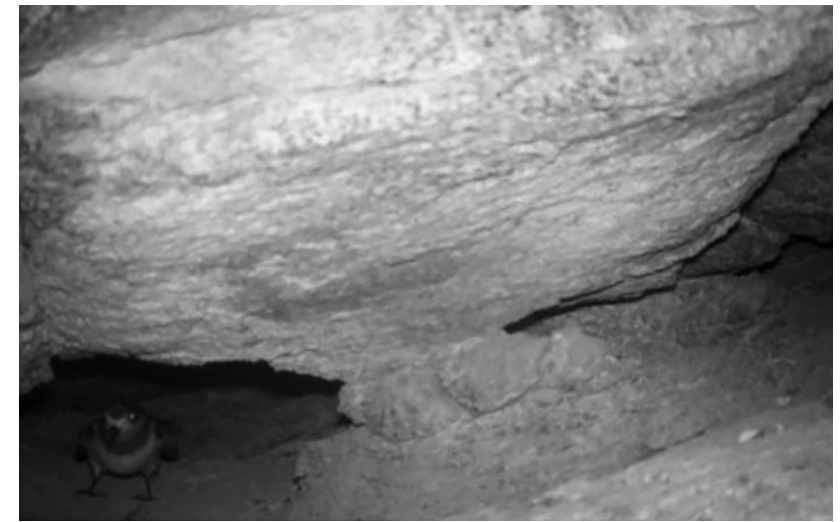

Hornby's storm petrel Oceanodroma hornbyi captured by a camera trap.

at $1,100 \mathrm{~m}, 75 \mathrm{~km}$ from the coast. Two breeding sites were recently reported in Chile: a single nest cavity at Salar de Quiuña, Tarapacá Region, and an individual leaving a cavity at Salar de Navidad, Antofagasta Region (Medrano et al., 2019, Revista Chilena de Ornitología, 25, 21-30). These breeding records are in natural shallow cavities in gypsum outcrops. Here, however, we describe the first record of Hornby's storm petrel breeding in a different environment.

On 13 February 2021, during research on rodents in a landscape dominated by abundant and steep rocky ravines with sparse vegetation, $12 \mathrm{~km}$ from the coast, at 1,050 m, c. $35 \mathrm{~km}$ south of Antofagasta, we recorded Hornby's storm petrel on a camera trap. The individual visited the nest, inside a small rocky cave, frequently, consistent with parental care. The main threats to the species in this area are loss and degradation of habitat and light pollution from mining, and solar and wind energy projects. In nearby areas we also recorded additional evidence of Hornby's storm petrel, in the form of feathers and faeces, suggesting a potential breeding colony.

RICARDo PINo RIFFo (๑ orcid.org/0000-0002-5510-9033)

Leopardus Austral Proyect, Santiago, Chile

E-mail r.pinovet@gmail.com

MARTA MORA ESPINOZA (๑ orcid.org/0000-0002-2821-0814) NGO Vida Nativa, Santiago, Chile

CRISTIAN SEPÚlVEDA CABRERA (@ orcid.org/0000-0002-18344472) Alianza Gato Andino, Santiago, Chile

This is an Open Access article, distributed under the terms of the Creative Commons Attribution licence CC BY 4.0.

\section{Illegal logging threatens to wipe out the Critically Endangered African zebrawood Microberlinia bisulcata from Cameroon's Ebo forest}

The African zebrawood Microberlinia bisulcata is a Critically Endangered species endemic to Cameroon. Demand for its 